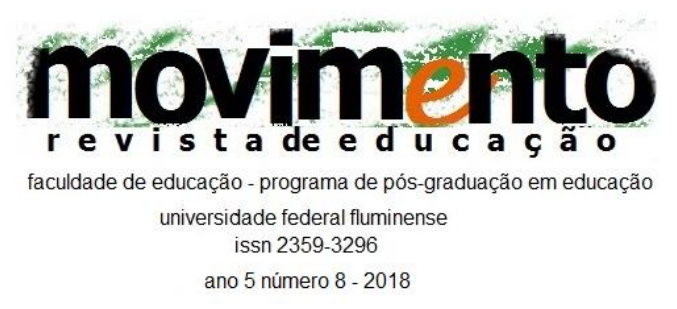

\title{
A GESTÃO DEMOCRÁTICA DAS ESCOLAS COMO REFERENCIAL POLÍTICO, EDUCATIVO E SIMBÓLICO: entrevista com o professor Licínio Lima
}

Daniela Patti do Amaral Universidade Federal do Rio de Janeiro,

Rio de Janeiro, RJ, Brasil

Entrevista com o professor Dr. Licínio C. Lima (Universidade do Minho, Portugal), realizada por e-mail, em dezembro de 2017.

A gestão democrática, presente nos documentos legais brasileiros que orientam as ações dos sistemas educacionais nos diferentes entes federados e nas escolas tem sido permanentemente objeto de debate, pesquisas, conflitos. A gestão democrática da escola não está dada, não se decreta nem se institui simplesmente por meio de uma legislação que a regulamente. A escola democrática exige estruturas democráticas e existe como processo, com avanços e recuos e demanda, sobretudo, práticas democráticas e participativas nos processos de tomada de decisões. No intuito de debater sobre os cenários que permeiam esse debate na escola pública brasileira contemporânea, convidamos o prof. Dr. Licínio Lima para dialogar e refletir sobre os desafios e tensões para a construção de uma agenda da gestão democrática das escolas públicas.

1. Acontecimentos recentes no campo da educação brasileira como o "escola sem partido", a decisão do Supremo Tribunal Federal favorável ao ensino religioso confessional nas escolas públicas e a militarização de escolas públicas estaduais têm provocado debates, polarizações e conflitos. Como garantir uma escola pública laica e democrática diante de tantas tensões? 


\section{movimento \\ faculdade de educação - programa de pós-graduação em educação universidade federal fluminense \\ issn 2359-3296 \\ ano 5 número 8 - 2018}

Uma escola pública, laica e democrática nunca esteve garantida no passado, não está garantida no presente e creio que nunca chegará a estar definitivamente garantida no futuro. Isso deve-se a várias razões, mas destacaria apenas duas. A primeira advém do próprio processo histórico de construção e institucionalização da escola moderna, digamos, ao longo dos últimos cento e cinquenta, duzentos anos. A escola, enquanto organização especializada, declarada universal, obrigatória e gratuita, capaz de produzir educação escolar em grande escala e de ensinar a todos como se fossem um só, designadamente através do uso de uma arte específica de ensinar "tudo a todos", como lhe chamou Coménio na sua Didática Magna, não só abriu as suas portas com dificuldade como democratizou o acesso ao conhecimento muito lentamente. Para além disso, adotou formas de organização e de governo frequentemente mais inspiradas em organizações religiosas, militares ou fabris do que em organizações cívicas e associativas de tipo cooperativo e de tendência democrática. Como costumo lembrar, não obstante o seu potencial de democratização do acesso à cultura e ao conhecimento científico e racional, a escola não foi criada para ser democrática: seja em termos de acesso, de permanência, de sucesso educativo, de organização e de estruturas de gestões administrativa e pedagógica, ou em termos de participação democrática no processo de tomada de decisões relativas ao seu governo. O controlo externo e as regras heterónomas, apesar dos mais recentes discursos sobre a autonomia das escolas, foram historicamente dominantes em termos de políticas e de práticas.

A segunda razão que aqui invoco prende-se, por um lado, exatamente com as profundas contradições entre os princípios constitucionais, a organização jurídica do Estado e da administração pública, os valores e as injunções que foram inscritos nas leis magnas da educação e no restante do ordenamento jurídico que foi produzido com a democratização dos regimes políticos em Portugal e no Brasil e, por outro, com as enormes resistências e dificuldades de 


\section{movimento \\ faculdade de educação - programa de pós-graduação em educação universidade federal fluminense \\ issn 2359-3296 \\ ano 5 número 8 - 2018}

realização efetiva de uma escola democrática. Durante os regimes ditatoriais, os setores democráticos de oposição lembraram justamente como a democratização da educação e das escolas, por vezes retoricamente prometida em contextos autoritários com intuitos de modernização e de pacificação social, só poderia ser realizada com a democratização política. No entanto, com a democratização dos regimes, com instituições políticas e constituições democráticas, descobrimos que talvez fosse mais fácil alcançar a democracia das formas e dos processos, das regras e do funcionamento das grandes organizações públicas, da competição interpartidária e de certas formas de representação do que propriamente democratizar a educação, a cultura, as mentalidades e as relações sociais de todo o tipo. A democratização política representava uma condição necessária, mas não suficiente para a democratização social, económica, cultural, educativa. Nesses campos, tudo se revelou mais lento e mais difícil de atingir, com avanços e recuos, com ideias generosas e, por vezes, enganosas, com realizações democráticas longamente reivindicadas e objeto de lutas sociais, mas, por outro lado, passíveis de retrocessos profundos em pouco tempo.

Tal como a democracia, a escola democrática nunca está garantida de uma vez por todas, para sempre. Exigirá processos permanentes de consolidação e de aprofundamento e esses não são possíveis à margem de práticas democráticas e participativas, do exercício de uma cidadania ativa e responsável, da velha virtude da coragem cívica de que já falavam os autores clássicos das teorias democráticas, ou seja, contra a passividade, o desinteresse, a alienação, a indecisão. Nesse sentido, a escola democrática não existe a não ser como processo. Ela exige estruturas e pré-requisitos democráticos e, simultaneamente, não pode deixar de contribuir para a sua reinvenção e o seu aprofundamento através de uma continuada ação educativa democrática. Esta, por sua vez, demanda práticas democráticas e participativas nos processos de tomada das decisões, única forma de aprender a democracia. 


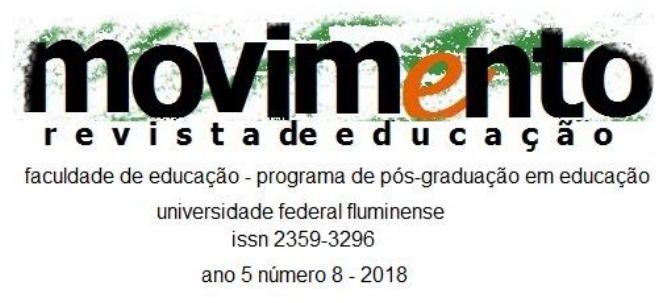

2. A gestão democrática das escolas públicas no Brasil ainda vive sob um regime de intenso patrimonialismo, especialmente em relação ao provimento das suas funções gestoras - diretor, coordenador/orientadores pedagógicos. Em 2014, a aprovação do Plano Nacional de Educação definiu a prioridade de repasse de transferências da União aos entes federados que contemplem o processo de seleção de diretores a partir de critérios técnicos. No entanto, boa parte dos municípios e dos estados ainda não regulamentou a gestão democrática em suas redes de educação.

- Nessa perspectiva, quais os desafios o senhor aponta para que o Brasil materialize uma escola democrática que não seja só no slogan?

A gestão democrática das escolas representa não apenas uma categoria teórica e até jurídica, mas também um referencial político e educativo de elevado valor simbólico. Corresponde a um ideal educativo e a um projeto de democratização política e social com expressão própria nas escolas e não a uma simples decorrência, mais ou menos mecânica, da democratização política de um regime. Tem uma história, um passado associado a lutas sindicais e estudantis. Foi palavra de ordem quando os atores educativos foram impedidos de ter voz própria e dissonante. Tudo isso constitui um capital político e educativo relevante, particularmente significativo para as gerações que viveram os tempos do autoritarismo, da repressão política, das esperanças, das lutas durante o processo de democratização e dos esforços empreendidos no sentido da consagração jurídica e formal de um princípio. Por todas as razões referidas, reduzir a gestão democrática das escolas a uma bandeira, a um slogan, independentemente da inspiração política ou doutrinária, representará uma profunda contradição e talvez um momento específico do processo da sua desvitalização simbólica em termos democráticos e da sua crise dos ideais de autogoverno das escolas. Quando se aceita que tudo, ou quase tudo, é compatível com uma gestão democrática das escolas, assim transformada em tecnologia de gestão articulável com os princípios da nova gestão pública e das práticas gerencialistas de inspiração empresarial, com práticas diversas de privatização e mercadorização da educação, com sistemas estandardizados de metas e formas tecnocráticas de mensuração, com parcerias público privadas 


\section{movimento \\ faculdade de educação - programa de pós-graduação em educação universidade federal fluminense \\ issn 2359-3296 \\ ano 5 número 8 - 2018}

que generalizam os seus sistemas pedagógicos, didáticos, avaliativos ou gestionários próprios, à prova de professores, ou já não se consegue descobrir nenhuma contradição significativa entre gestão democrática e nomeação de diretoras e outros detentores de cargos de gestão, isso significa que o ideal e o princípio normativo já perderam toda a sua potência democrática. Então o desafio é, como diz a canção de Ivan Lins, "começar de novo", afiar a criticidade, aumentar a exigência, ousar práticas democráticas novas, nunca desistir, não fazer de conta.

\section{- Como o senhor pensa os critérios de mérito e de desempenho e a consulta à comunidade no processo de seleção de diretores de escolas públicas?}

Existem tantas e tão diversificadas formas democráticas de selecionar diretores e diretoras de escolas públicas que só uma orientação tecnocrática seria capaz de as reduzir assim, apontando para uma solução pretensamente ótima e, como tal, de vigência universal, fora da qual todas as outras opções seriam consideradas exemplos de irracionalidades de gestão. Se queremos critérios de escolha democrática daqueles que ocuparão funções de direção escolar, talvez seja oportuno lembrar que a democracia não pode ser reduzida ao ato de jogar um jogo com regras integral e definitivamente dadas pelos outros (a que chamamos heteronomia, em vez de autonomia). Depois, seria oportuno saber o que significa dirigir uma escola e perguntar quem, na prática, realmente a está dirigindo. Será a diretora? Como estudo esta questão há muitos anos, tenho, pela minha parte, as maiores dúvidas. Será que o verdadeiro órgão de direção política e estratégica de cada escola se localiza no seu interior? Ou será que reside em autoridades situadas acima e para além dela? A diretora dirige ou, sobretudo, executa, de forma política e administrativamente subordinada, as decisões políticas que alguém já decidiu que ela operacionalizaria? Em qualquer dos casos, por que razão, no âmbito de uma gestão democrática da escola, haveríamos, necessariamente, de escolher um órgão unipessoal (diretor ou 


\section{movimento \\ faculdade de educação - programa de pós-graduação em educação universidade federal fluminense \\ issn 2359-3296 \\ ano 5 número 8 - 2018}

diretora) e não um órgão colegiado, composto por várias pessoas e coordenado ou presidido por uma delas? E, quanto ao modelo organizacional, às estruturas e aos órgãos, a gestão democrática da escola inclui a possibilidade de, no cumprimento dos princípios democráticos da lei geral, desenhar o modelo organizacional concreto e decidir sobre a existência de um órgão de direção colegial ou unipessoal? E, se nada disso puder ser decidido democraticamente nas escolas, ainda haverá razões substantivas para continuarmos a falar de gestão democrática das escolas? Como se vê, as minhas dúvidas são muitas. 0 que me parece é que a eleição, a colegialidade e a prática de decisões democráticas minimamente relevantes representam dimensões centrais do conceito de gestão democrática.

A nomeação do diretor garante sobretudo a confiança política da entidade externa que o escolheu e que, depreende-se, também é responsável pela elaboração do projeto educativo da escola. Sendo dotada de legitimidade democrática, a autoridade externa parece limitar a democracia a um ato primordial que a terá legitimado e, após tal ação, entende que tem todo o direito de realizar uma gestão democrática, a partir de fora e de cima, sobre a escola. A designação por concurso acentua a dimensão técnica do perfil de diretor, ou seja, um especialista que, uma vez provido por ter ganhado o respectivo concurso, será responsável pela execução do projeto político para a escola não elaborado por ele, em princípio, pois não teria legitimidade democrática para tanto. Apesar da dimensão técnica e formativa ser relevante, ela está subordinada à questão política democrática e, se a diretora ou o diretor é um órgão unipessoal técnico, faltará saber qual será o órgão democrático de direção política e estratégica na escola. Creio que a eleição por representantes da comunidade escolar alargada, com base na apresentação de projetos educativos, com duração limitada de mandatos exercidos por órgãos colegiados, seja uma possibilidade a ponderar e que comporte múltiplas e diferenciadas soluções. Para além de tudo isso, que é relevante, importa não ignorar as 


\section{movimento \\ faculdade de educação - programa de pós-graduação em educação universidade federal fluminense \\ issn 2359-3296 \\ ano 5 número 8 - 2018}

condições básicas para o exercício da democracia nas escolas: diálogo, debate, argumentação, capacidade de ter voz e de ouvir o outro, legitimidade dos interesses e das agendas divergentes se expressarem livremente e formas democráticas de dirimir os conflitos. Sem uma cultura democrática em exercício no quotidiano das escolas, o que seria, afinal, a gestão democrática? Apenas um conjunto de regras e processos? Um método de escolha dos líderes? Uma eleição primordial que depois dispensaria todas as vivências e os conteúdos democráticos ulteriores? Ou seria um conjunto de órgãos democraticamente eleitos, mas depois inibidos de participarem na co-governação das escolas com outras autoridades nas esferas municipal, estadual, federal?

\section{Sobre os desafios da gestão em escolas públicas no Brasil e em Portugal - Como trabalhar a perspectiva de uma gestão democrática em épocas de performatividade nas escolas?}

A questão é muito oportuna e, à luz do que já afirmei antes, creio que estaremos perante a contradições potencialmente insanáveis. A menos que tenhamos da gestão democrática das escolas uma concepção apenas procedimentalista, subordinada ao cumprimento de certas regras e ao estabelecimento de certas estruturas formais e, por isso, dependente de uma racionalidade formal ou instrumental, será difícil deixar de concluir que o atual ambiente de competição exacerbada entre escolas e no interior delas se revela mais meritocrático do que democrático. Uma educação contábil, como a defino há mais de duas décadas, que procura uma matematização irrestrita da realidade educacional de professores e de alunos, que é de natureza "quantofrénica" (para usar um conceito proposto criticamente pelo sociólogo Pitirim Sorokin) e que, por isso, revela-se incapaz de aceitar o incomensurável em educação, acaba por subjugar a ação educativa à quantificação, ao cálculo, à comparação e à correspondente hierarquização. Tudo isso é mais congruente com a competição, a seleção e a distinção social do que com a democratização, a integração e a solidariedade. 


\section{movimento \\ faculdade de educação - programa de pós-graduação em educação universidade federal fluminense \\ issn 2359-3296 \\ ano 5 número 8 - 2018}

Como a qualidade e a excelência escolares são geralmente definidas como propriedades raras e atributos escassos do ponto de vista da sua distribuição estatística no interior de uma dada população - por isso justificando as políticas de reconhecimento do mérito a partir dos resultados alcançados pelos alunos em exames - a democracia tem sido substituída pelo elogio da meritocracia. Esta seria uma forma de governo baseada na "aristocracia do talento", como criticamente lhe chamou Michael Young em 1958, em que o mérito resultaria da soma da inteligência com o esforço. Uma adição realizada de forma puramente individual por cada aluno, destacando a vontade e tendendo a desprezar todas as condicionantes relacionadas com as profundas diferenças de tipo socioeconómico e cultural. É, contudo, em um contexto de crescente elitização educacional que esse tipo de oligarquia educativa se revela incompatível com a democratização da educação escolar. A menos que, como por vezes parece, admita-se a gestão formalmente democrática de uma escola meritocrática. Em tal caso, porém, a dita gestão teria já sido amputada de qualquer substantividade democrática para ser reduzida a mínimos democráticos em termos instrumentais (algumas regras e alguns processos, eventual eleição de certos órgãos etc.), uma situação em que esse tipo de gestão acabaria se vendo reduzida a um slogan legitimador, a muita gestão tecnocrática para pouca ou nula educação democrática.

\section{- É possível uma liderança democrática na escola?}

Em um quadro marcado por uma forte erosão das políticas e das práticas de gestão democrática das escolas, a liderança emergiu como conceito político central, com grande expressão nas legislações escolares, como acontece em Portugal. No entanto, não se invoca a expressão liderança democrática. Liderança forte, unipessoal, clara, competente, eficaz são as expressões mais comuns, de extração empresarial. O líder executivo eficaz representa um topos na literatura da gestão empresarial, pelo menos desde a década de 1930 e da chamada Escola das Relações Humanas, fortemente associada à cooperação, 


\section{movimento \\ faculdade de educação - programa de pós-graduação em educação universidade federal fluminense \\ issn 2359-3296 \\ ano 5 número 8 - 2018}

à harmonia, funcionalmente colocadas a serviço de uma ordem hierárquica e consensual, e à cooptação dos membros da organização e a um certo participacionismo, como Ihe chamou Maurício Tragtenberg, no sentido de uma participação periférica e insular relativamente à tomada das decisões políticas. Quer dizer, a liderança unipessoal eficaz veio substituir o discurso da gestão democrática. Encontrar a pessoa certa para o lugar certo, a liderança eventualmente carismática, passível de ser individualmente responsabilizada perante as autoridades educacionais e os, agora designados, stakeholders, parece o caminho racional.

Claro que é teoricamente possível discutir a liderança, individual e coletiva, no contexto de uma gestão democrática das escolas, designadamente através de conceitos como liderança democrática, distribuída, transacional, transformacional, etc. Para quem pesquisa esse tema, contudo, uma das primeiras questões a estudar é saber por que razões a problemática da liderança ganhou, nos últimos anos, tanto protagonismo. Por que a liderança e por que agora? E por que em um contexto que, em simultâneo, fez evacuar do discurso político e legislativo a direção democrática das escolas e, no caso português, mesmo a categoria gestão democrática, embora esta permaneça na Constituição da República Portuguesa e na Lei de Bases do Sistema Educativo? Com efeito, entendo que a influência crescente do novo gerencialismo na educação, desde as abordagens da "reinvenção do governo", passando pela mais genérica e sincrética "nova gestão pública" até à "nova governança", inflacionou a importância da gestão e dos gestores no mundo da educação. À semelhança das empresas, o gestor e o seu "direito de gerir", através da sua visão, do seu programa, da sua equipa e dos seus assessores, bem como dos seus métodos especializados e das suas técnicas de gestão, emergiu como o pivot das mudanças a introduzir nas escolas. O próprio conceito de autonomia de gestão, no sentido de autonomia do gestor, sobrepôs-se à autonomia da escola, à profissional de educadoras e professores, à pedagógica, etc. Agora, 


\section{movimento \\ faculdade de educação - programa de pós-graduação em educação universidade federal fluminense \\ issn 2359-3296 \\ ano 5 número 8 - 2018}

portanto, a liderança parece desconectada do projeto de democratização da educação e do autogoverno das escolas para passar a estar mais relacionada com a modernização das escolas, a sua racionalização e a produção de resultados em ambiente competitivo. E, ao ser apresentada como alternativa à gestão democrática, a liderança parece definir-se, naturalmente, como individual, assim rompendo com a ação de órgãos colegiados anteriores (como acontece em Portugal desde 2008 com a substituição de conselhos por diretores). Nesse sentido, a liderança ou seria individual ou não seria liderança, uma vez que, ideologicamente, mesmo contra as conclusões da pesquisa disponível, a liderança colegiada passou a ser considerada uma impossibilidade ou uma irresponsabilidade, dando origem a resultados desastrosos.

\section{Sobre as produções acadêmicas/científicas da gestão escolar, o senhor acredita que temos avançado na perspectiva teórico-metodológica no Brasil e em Portugal?}

Tudo depende do lapso temporal incluído nessa apreciação. Para quem iniciou os seus estudos sobre administração educacional no Portugal de meados da década de 1970, os avançados académicos registados desde então foram notáveis. Recorde-se que, nessa altura, embora com quase um século de história no ensino da administração escolar no contexto da formação inicial de professores, só a democratização ocorrida na sequência da revolução democrática do 25 de abril de 1974 permitiria o progressivo afastamento das perspectivas jurídicas e normativas ou daquilo a que Benno Sander, referindose ao Brasil, chamou "enfoque jurídico". A rejeição da administração escolar como mera interpretação jurídica ou, ainda, como reprodução e aplicação à educação de uma pretensa teoria geral da administração, oriunda do mundo empresarial (sobretudo de influência inicialmente fayolista), que haveria de ser criticada em Portugal e no Brasil, designadamente por Vitor Paro no caso brasileiro, abriu novos horizontes teóricos e metodológicos à disciplina e 


\section{movimento \\ faculdade de educação - programa de pós-graduação em educação universidade federal fluminense \\ issn 2359-3296 \\ ano 5 número 8 - 2018}

possibilitou a sua inscrição nas ciências sociais e da educação. Várias linhas de desenvolvimento puderam ser rasgadas a partir de então, buscando articulações teóricas e diálogos produtivos entre a administração educacional e as teorias da administração pública, das organizações, a psicologia social e do trabalho, a sociologia das organizações, a ciência política, entre outras. No caso português, a procura de relações entre a administração educacional, escolar e não escolar, e a sociologia das organizações educativas e a política educacional correspondeu a um projeto académico capaz de resgatar o ensino e a pesquisa da administração educacional das abordagens tradicionalmente jurídicas e normativistas. Ainda hoje, volvidas quatro décadas, e não obstante outras opções que, entretanto, emergiram - em certos casos, parecendo retomar abordagens normativistas e doutrinárias de feição pragmática em prejuízo de uma vocação interpretativa e analítica crítica - continua a tratar-se da orientação com maior vigor teórico e metodológico, responsável pelo desenvolvimento da disciplina e por atividades sistemáticas de pós-graduação e de pesquisa, com status e projeção internacionais. Dispomos hoje de um importante acervo de investigações teóricas e empíricas que não tem paralelo com qualquer outro período histórico. Creio que algo de semelhante ocorre no Brasil. O intercâmbio académico iniciado, nessa área, há mais de duas décadas entre os dois países, é revelador disso mesmo. E revela ainda, paradoxalmente, como a produção académica sobre administração escolar só recentemente "descobriu" a escola como objeto de estudo e se adentrou nela, recusando condená-la à condição de um mero reflexo das macrodecisões políticas e respetivas medidas legislativas e regulamentares, embora estas nunca deixem de influenciar os contextos organizacionais escolares. Como tenho vindo a insistir há mais de três décadas, cada escola não é apenas um lócus de reprodução normativa, é também um lugar de produção de orientações e de regras.

Certamente, existe ainda muito caminho para percorrer no sentido de consolidar e desenvolver o ensino e a pesquisa em administração educacional (ou gestão 


\section{movimento \\ faculdade de educação - programa de pós-graduação em educação universidade federal fluminense \\ issn 2359-3296 \\ ano 5 número 8 - 2018}

educacional). Não me refiro tanto a questões terminológicas interessantes, mas talvez pouco produtivas, como a implícita na eventual distinção entre administração e gestão, uma questão que se encontra equacionada em certas línguas e por certas correntes teóricas há mais de um século, mas que, em língua portuguesa, parece hoje mais dependente de conotações circunstanciais do que teoricamente substantivas. Refiro-me a desafios teóricos cruciais, como o de conseguirmos desvincular a teoria da administração educacional das reminiscências doutrinais e prescritivas do mundo empresarial e dos negócios, reforçando os seus vínculos com as teorias da educação e a pedagogia, com a política educacional e a sociologia da administração e das organizações, entre outros referenciais de vocação analítica. Por isso, tenho defendido a distinção entre abordagens normativas e pragmáticas (uma tradição a exigir movimentos de ruptura e superação) e abordagens analíticas e interpretativas (um movimento alternativo em direção ao reforço da pesquisa e da compreensão, e não mais da doutrinação e da prescrição). Creio que, só a partir dessa distinção, que é conceitual, poderemos libertar-nos das ideologias e das prescrições mais típicas das doutrinas da gestão, procedendo à sua crítica, e inscrevermos os nossos trabalhos na teoria social e nas correspondentes correntes e controvérsias.

Isso significa, portanto, que existem problemas no nosso campo de estudos que necessitam ser afrontados e superados. Uma vez tendo ultrapassado dependências, vínculos ideológicos e tecnocráticos tradicionais, é oportuno refletir criticamente sobre a pouca autonomia do nosso campo de estudos e sobre as dificuldades que evidencia quanto a construir agendas de investigação próprias e com certa continuidade e sistematicidade, certamente interrogando as políticas e as práticas atuais de organização e gestão, mas recusando subordinar-se às agendas políticas e aos seus ritmos próprios, colar-se em demasia aos temas do legislador, adotar as suas linguagens e os seus conceitos. Sendo verdade que as questões teóricas e metodológicas têm ganhado 


\section{movimento \\ faculdade de educação - programa de pós-graduação em educação universidade federal fluminense \\ issn 2359-3296 \\ ano 5 número 8 - 2018}

importância nas nossas produções académicas e que existe uma nova geração de pesquisadores particularmente interessada no seu estudo, ainda é bem visível o quanto a atividade de publicação e a apresentação de trabalhos em reuniões científicas continua dependente das agendas políticas e das ações administrativas de cada momento, sucedendo-se em função dos temas da pauta institucional e das suas cadências específicas. Se não prosseguirmos e aprofundarmos os esforços de consolidação teórica e metodológica da gestão escolar como disciplina académica e como atividade de pesquisa, no contexto das ciências humanas e sociais, mais dificilmente concluiremos o processo de renovação iniciado nas últimas décadas e, pelo contrário, mais facilmente voltaremos a ficar à mercê de dinâmicas gerencialistas e doutrinárias que seria suposto sermos capazes de interpretar e criticar.

\section{SOBRE A ENTREVISTADORA}

DANIELA PATTI DO AMARAL é Professora Associada da Faculdade de Educação da Universidade Federal do Rio de Janeiro (UFRJ). Doutora em educação pela mesma instituição.

E-mail: danielapatti.ufri@gmail.com

\section{SOBRE O ENTREVISTADO}

LICÍNIO C. LIMA é Doutor em Educação. Professor Catedrático do Instituto de Educação da Universidade do Minho (Braga, Portugal).

E-mail: llima@ie.uminho.pt 